\title{
ANALISIS PENGGUNAAN TANDA BACA PADA TEKS NARASI SISWA KELAS VII SMPN 2 KAPUR IX
}

\author{
Indah Rahma Fitri ${ }^{1}$, Rama Kurnia Wahyuni ${ }^{2}$ \\ Program Studi Pendidikan Bahasa dan Sastra Indonesia, Fakultas Bahasa dan Seni \\ Universitas Negeri Padang \\ ${ }^{1}$ Rahma1781@gmail.com, 22Ramakurniawahyuni@gmail.com
}

\begin{abstract}
Abstrak
Tujuan dari penelitian adalah untuk menganalisis kesalahan penggunaan tanda baca titik (.) dan tanda baca tanya (?) pada teks narasi .Metode penelitian yang digunakan metode deskriptif kualitatif. Setelah menganalisis kesalahan dari 40 data karangan narasi yang dibuat oleh 40 siswa terdapat total kesalahan adalah 205, akhirnya penulis menarik simpulan bahwa kesalahan penggunaan tanda titik (80\%) dan tanda baca tanya $(20 \%)$.
\end{abstract}

Kata Kunci: Penggunaan Tanda Baca, Teks Narasi

\begin{abstract}
The purpose of this research is to know the error experienced by someone who wants to read narrative text. Qualitative descriptive research method. After analyzing the errors of 40 data narrative made by 40 students there is a total error of 205 , one is interested in mark error (80\%) and question mark (20\%).
\end{abstract}

Keywords: Use of Punctuation, Narrative Text

\section{PENDAHULUAN}

Dalam pembelajaran Bahasa Indonesia ada empat aspek keterampilan yang wajibdimiliki oleh siswa. Keempat aspek keterampilan berbahasa itu adalah mendengarkan, berbicara, membaca dan menulis. Empat aspek tersebut merupakan keterampilan yang memiliki peranan penting dalam berbagai aspek kehidupan dan saling berkaitan antara satudengan yang lainnya. Dari keempat aspek keterampilan berbahasa di atas, keterampilan menulis merupakan salah satu keterampilan yang tidak mudah untuk dikuasai oleh siswa. Untuk dapat menguasai keterampilan menulis siswa dituntut untuk terus berlatih agar dapat menghasilkan sebuah tulisan yang baik dan sesuai dengan kaidah bahasa
Indonesia. Banyak siswa yang menganggap keterampilan menulis merupakan keterampilan yang rumit karena untuk dapat menguasai keterampilan menulis siswa harus memahami seluruh aspek penulisan dengan baik.

Keterampilan menulis dibutuhkan oleh siswa ketika siswa membuat sebuah karangan teks. Dalam pembelajaran Bahasa Indonesia, ada beberapa jenis teks yang dipelajari oleh siswa. Jenis-jenis teks tersebut yaitu teks narasi, teks eksposisi, teks deskripsi, teks argumentasi, dan tekspersuasi. Dalam penelitian ini penulis akan meneliti keterampilan menulis dalam teks narasi. Sebelum menulis teks narasi, siswa harus memahami apa itu teks narasi. Teks 
narasi merupakan karangan yang menceritakan sebuah peristiwa dengan urutan waktu yang jelas dari awal, tengah hingga akhir. Teks narasi biasanya dikemas dengan baik agar dapat mengibur pembacanya baik itu bersifat fiksi maupun non fiksi. Dalam membuat teks narasi yang menarik dan dapat menghibur pembacanya, penulis perlu memperhatikan tanda baca pada penulisan dalam teks narasi. Oleh karena itu, penulis melatih dan menguji keterampilan menulis siswa dalam menulis teks narasi untuk memperhatikan tanda baca pada penulisan karangan narasi siswa.

Tanda baca yang diteliti penulis dalam penelitian ini dikhususkan pada tanda baca titik dan tanda baca tanya. Penulis akan melihat kemampuan siswa dalam memahami penggunaan tanda baca titik dan tanda baca Tanya dalam menulis teks narasi. Setelah dilakukannya penelitian ini, penulis berharap dapat mengetahui tingkat pemahaman siswa dalam penggunaan tanda baca terkhusus pada tanda baca titik dan tanda baca tanya. Dengan demikian diharapkan siswa dapat menyadari dan mengetahui kesalahan yang mereka buat,sehingga siswa dapat menulis dengan benar sesuai dengan penggunaan tanda baca yang baik dan benar.

\section{Hakikat Menulis}

Menurut Cahyani (dalam skripsi Ilmia Rajab, 2017 : 27 ) menulis adalah: Keterampilan produktif dengan menggunakan tulisan. Menulis dapat dikatakan suatu keterampilan berbahasa yang rumit diantara jenis-jenis keterampilan yang lainnya. Karena menulis bukanlah sekedar menyalin katakata dan kalimat, melainkan juga mengembangkan dan menuangkan pikiran-pikiran dalam suatu struktur tulisan yang teratur.
Menurut Tarigan (2008: 22) menulis adalah menurunkan atau melukiskan lambang-lambang grafis yang menghasilkan suatu bahasa yang dipahami oleh seseorang sehingga orang lain dapat membaca lambanglambang grafis tersebut dan dapat memahami bahasa dan grafis itu.

Menurut Suparno dan Yunus (2003: 13) aktivitas menulis melibatkan beberapa unsur, yaitu penulis sebagai penyampaian pesan, isi tulisan, saluran atau media, dan pembaca. Menulis merupakan suatu kegiatan penyampaian pesan (komunikasi) dengan menggunakan bahasa tulis sebagai alat atau medianya.

Dari uraian pendapat para ahli di atas dapat disimpulkan bahwa menulis adalah suatu kegiatan menuangkan ide dalam bentuk lambang-lambang tulisan yang bertujuan untuk menyampaikan pesan dalam bentuk tulisan.

\section{Hakikat Teks Narasi}

Karangan narasi adalah suatu bentuk tulisan yang berusaha menciptakan, mengisahkan, merangkaikan tindaktanduk perbuatan manusia dalam sebuah peristiwa secara kronologis atau yang berlangsung dalam suatu kesatuan waktu (dalam jurnal Yera, 2014).

Narasi adalah suatu bentuk wacana yang sasarannya adalah tindaktanduk yang dijalin dan dirangkai menjadi sebuah peristiwa yang terjadi dalam suatu kesatuan waktu atau dapat juga diartikan sebagai suatu bentuk wacana yang berusaha menggambarkan sejelas-jelasnya kepada pembaca suatu peristiwa yang telah terjadi (Keraf, 2000:136).

Narasi adalah karangan yang berupa rangkaian peristiwa yang berdasarkan urutan waktu. Karangan yang termasuk jenis ini adalah karangan fiksi, seperti novel, 
cerpen, dan roman. (Abdul Munif.2007:5)

Dari beberapa pendapat para ahli tersebut dapat disimpulkan bahwa narasi adalah karangan yang menceritakan sebuah peristiwa menurut urutan waktu dari awal, tengah hingga akhir, sehingga pembaca seolah-seolah ikut mengalami peristiwa yang di ceritakan tersebut.

\section{Hakikat Penggunaan Tanda Baca}

Penggunaan tanda baca dalam kegiatan menulis harus baik dan benar, untuk itu setiap siswa harus benar-benar memahami penggunaan tanda baca dengan baik agar hasil tulisan yang dibuatnya menarik untuk dibaca. Tanda baca disebut juga pungtuasi. Pungtuasi atau tanda baca tanda sebagai hasil usaha menggambarkan unsur-unsur suprasegmental itu tidak lain dari gambar atau tanda yang secara konvensional disetujui bersama untuk memberikan kunci kepada pembaca terhadap apa yang ingin disampaikan kepada mereka (dalam skripsi Handayani Nasution, 2013). Tanda baca menurut Gani dan Fitriyah (dalam jurnal Ilmia Rajab, 2017:9) "dapat membantu seseorang dalam memahami isi bacaan. Coba bayangkan jika sebuah teks atau wacana tidak menggunakan tanda baca. Sudah tentu, bacaan tersebut tidak dapat dipahami”. Suparno, dkk (dalam jurnal Nurmawati, dkk 2013 : 136), mengemukakan bahwa tanda baca adalah tanda-tanda yang digunakan di dalam bahasa tulis agar kalimat yang kita tulis dapat dipahami orang persis seperti kita maksudkan. Chaer (dalam jurnal Sri Dewi Astuti, dkk. hal. 16) "mengemukakan tanda baca adalah tanda-tanda yang digunakan di dalam bahasa tulis agar kalimat yang kita tulis dapat dipahami orang persis seperti apa yang kita maksudkan".
Dari pendapat diatas dapat disimpulkan bahwa tanda baca adalah tanda-tanda yang digunakan didalam sebuah tulisan yang bertujuan membuat pembacanya lebih mudah memahami maksud dari tujuan tulisan tersebut.

Dalam penelitian ini penulis akan meneliti penggunaan tanda baca titik dan tanda baca tanya dalam tulisan yang di buat oleh siswa.

\section{a. Tanda Baca Titik}

Tanda titik menurut Sugono, dkk. (dalam skripsi Ilmia Rajab, 2017:10) merupakan "tanda yang biasanya dipakai untuk menandai akhir sebuah kalimat. lambang dari tanda titik yaitu (.)".

Kaidah penulisan tanda titik, berdasarkan pedoman umum EBI (Ejaan Bahasa Indonesia) Peraturan Menteri Pendidikan dan Kebudayaan Republik Indonesia No. 50 Tahun 2015 adalah sebagai berikut :

1) Tanda titik di pakai pada akhir kalimat pernyataan.

2) Tanda titik dipakai di belakang angka atau huruf dalam suatu bagan, ikhtisar, atau daftar.

3) Tanda titik dipakai untuk memisahkan angka jam, menit, dan detik yang menunjukkan waktu atau jangka waktu.

4) Tanda titik dipakai dalam daftar pustaka di antara nama penulis, tahun, judul tulisan (yang tidak berakhir dengan tanda tanya atau tanda seru), dan tempat terbit.

5) Tanda titik dipakai untuk memisahkan bilangan ribuan atau kelipatannya yang menunjukkan jumlah.

b. Tanda Baca Tanya

Kaidah penulisan tanda tanya, berdasarkan pedoman umum EBI 
(Ejaan Bahasa Indonesia) Peraturan Menteri Pendidikan dan Kebudayaan Republik Indonesia No. 50 Tahun 2015 adalah sebagai berikut :

1) Tanda tanya dipakai pada akhir kalimat tanya

2) Tanda tanya dipakai di dalam tanda kurung untuk menyatakan bagian kalimat yang disangsikan atau yang kurang dapat dibuktikan kebenarannya.

\section{METODE PENELITIAN}

Sampling Jenuh adalah teknik menentukan sampel bila semua anggota populasi digunakan sebagai sampel. Hal ini sering dilakukan bila jumlah populasi yang relatif kecil. Dalam penelitian ini yang jumlah sampel sama dengan jumlah populasi yang diteliti, yaitu 40 orang siswa kelas VII. Metode yang digunakan adalah deskriptif kualitatif dengan teknik pengumpulan data berupa tes. Analisis data yaitu dengan membaca seluruh karangan narasi yang akan dijadikan objek penelitian, menganalisis tanda baca titik dan tanda tanya, hasil dari analisis data tersebut kemudian diberikan interpretasi sesuai tingkat kesalahannya dengan berpedoman Panduan Umum Ejaan Bahasa Indonesia.

\section{HASIL DAN PEMBAHASAN}

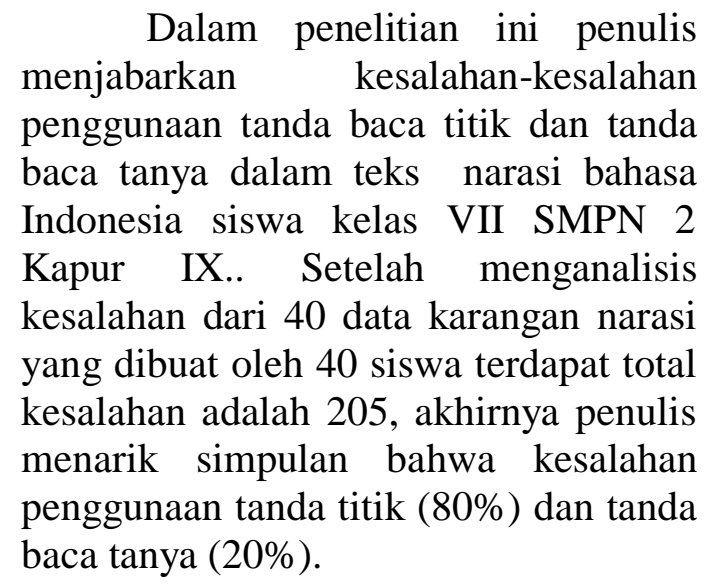

Tabel 1 Persentase Kesalahan Penggunaan

Tanda Baca Titik dan Tanda Baca Tanya

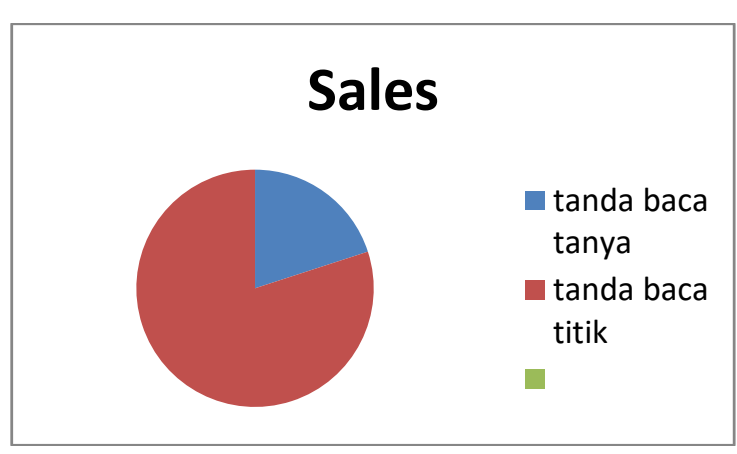

Berdasarkan tabel tersebut kesalahan yang paling banyak ditemukan adalah kesalahan penggunaan tanda baca yaitu sebanyak $80 \%$ dan kesalahan penggunaan tanda baca sebanyak $20 \%$.

Kesalahan tersebut dapat dilihat pada tabel di bawah ini.

\begin{tabular}{|c|c|c|c|}
\hline $\begin{array}{l}\mathbf{N} \\
\mathbf{O}\end{array}$ & $\begin{array}{l}\text { NAMA } \\
\text { SISWA }\end{array}$ & KALIMAT & $\begin{array}{l}\text { KESALAH } \\
\text { AN }\end{array}$ \\
\hline \multirow[t]{2}{*}{1} & $\begin{array}{l}\text { SALSA } \\
\text { BILA } \\
\text { PUTRI }\end{array}$ & $\begin{array}{l}\text { Pada hari } \\
\text { minggu aku } \\
\text { mengunjingi } \\
\text { rumah } \\
\text { neneku }\end{array}$ & $\begin{array}{l}\text { Tidak } \\
\text { menggunak } \\
\text { an tanda } \\
\text { titik pada } \\
\text { akhir } \\
\text { kalimat }\end{array}$ \\
\hline & & $\begin{array}{l}\text { Aku } \\
\text { bertanya } \\
\text { pada } \\
\text { neneku, } \\
\text { dimanakah } \\
\text { tempat } \\
\text { paling indah } \\
\text { di } \\
\text { kampungku } \\
\text { ini }\end{array}$ & $\begin{array}{l}\text { Tidak } \\
\text { menggunak } \\
\text { an tanda } \\
\text { tanya pada } \\
\text { akhir } \\
\text { kalimat } \\
\text { yang } \\
\text { merupakan } \\
\text { kalimat } \\
\text { tanya }\end{array}$ \\
\hline $\begin{array}{l}\mathbf{N} \\
\mathbf{O}\end{array}$ & $\begin{array}{l}\text { NAMA } \\
\text { SISWA }\end{array}$ & KALIMAT & $\begin{array}{l}\text { KESALAH } \\
\text { AN }\end{array}$ \\
\hline 2 & $\begin{array}{l}\text { SITI } \\
\text { NURZA } \\
\text { INAB }\end{array}$ & $\begin{array}{lr}\text { Hari } & \text { ini } \\
\text { adalah } & \text { hari } \\
\text { yang } & \\
\end{array}$ & $\begin{array}{l}\text { Tidak } \\
\text { menggunak } \\
\text { an tanda }\end{array}$ \\
\hline
\end{tabular}




\begin{tabular}{|l|l|l|}
\hline & $\begin{array}{l}\text { menyenangk } \\
\text { an bagiku }\end{array}$ & $\begin{array}{l}\text { titik pada } \\
\text { akhir } \\
\text { kalimat }\end{array}$ \\
\hline & $\begin{array}{l}\text { Aku } \\
\text { bertemu } \\
\text { dengan } \\
\text { sahabat } \\
\text { lamaku }\end{array}$ & $\begin{array}{l}\text { Tidak } \\
\text { menggunak } \\
\text { an tanda } \\
\text { tanya pada } \\
\text { akhir } \\
\text { kalimat } \\
\text { yang } \\
\text { merupakan } \\
\text { kalimat } \\
\text { tanya }\end{array}$ \\
\hline
\end{tabular}

\begin{tabular}{|c|c|c|c|}
\hline $\begin{array}{l}\mathbf{N} \\
\mathbf{O}\end{array}$ & $\begin{array}{l}\text { NAMA } \\
\text { SISWA }\end{array}$ & KALIMAT & $\begin{array}{l}\text { KESALAH } \\
\text { AN }\end{array}$ \\
\hline 3 & $\begin{array}{l}\text { FIJRA } \\
\text { ZAHAR } \\
\text { A }\end{array}$ & $\begin{array}{l}\text { Libura tahun } \\
\text { ini aku } \\
\text { habiskan di } \\
\text { rumah }\end{array}$ & $\begin{array}{l}\text { Tidak } \\
\text { menggunak } \\
\text { an tanda } \\
\text { titik pada } \\
\text { akhir } \\
\text { kalimat }\end{array}$ \\
\hline & & $\begin{array}{l}\text { Adikku } \\
\text { merengek, } \\
\text { dimana } \\
\text { mama? }\end{array}$ & $\begin{array}{l}\text { Tidak } \\
\text { menggunak } \\
\text { an tanda } \\
\text { tanya pada } \\
\text { akhir } \\
\text { kalimat } \\
\text { yang } \\
\text { merupakan } \\
\text { kalimat } \\
\text { tanya }\end{array}$ \\
\hline
\end{tabular}

Berdasarkan tabel kesalahan siswa di atas dapat disimpulkan jika masih banyak siswa yang salah dalam penggunaan tanda baca titik dan tanda baca tanya. Selain itu siswa tidak tahu penempatan yang tempat untuk tanda baca titik dan tanda baca tanya.

Pada penelitian ini juga ditemukan beberapa penyebab keselahan penggunaan tanda baca titik dan penggunaan tanda baca tanya oleh siswa

1. Kurangnya pengetahuan siswa tentang penggunaan tanda baca titik dan tanda baca tanya yang tepat.
2. Kurangnya perhatian siswa dalam menulis khususnya saat penggunaan tanda baca titik dan tanda baca tanya.

3. Tidak adanya kepedulian guru dalam penggunaan tanda baca titik dan tanya baca tanya yang dituliskan oleh siswa pada teks narasi, sehingga kesalahan yang dilakukan oleh siswa tidak ada perbaikan atau perevisian.

\section{SIMPULAN}

Dari penelitian yang dilakukan oleh penulis dapat disimpulkan beberapa penyebab keselahan penggunaan tanda baca titik dan penggunaan tanda baca tanya oleh siswa

1. Kurangnya pengetahuan siswa tentang penggunaan tanda baca titik dan tanda baca tanya yang tepat.

2. Kurangnya perhatian siswa dalam menulis khususnya saat penggunaan tanda baca titik dan tanda baca tanya.

3. Tidak adanya kepedulian guru dalam penggunaan tanda baca titik dan tanya baca tanya yang dituliskan oleh siswa pada teks narasi, sehingga kesalahan yang dilakukan oleh siswa tidak ada perbaikan atau perevisian.

\section{DAFTAR PUSTAKA}

Rajab, I. (2017). Analisis Penggunaan Tanda Baca Dalam Menulis Teks Laporan Hasil Observasi Siswa Kelas X Sma Negeri 1 Pangkajene Kabupaten Pangkep.Makassar: Universitas Negeri Makassar

Nurmawati dkk. (2013). Peningkatan Kemampuanmenggunakan

Tanda Baca Titik, Koma, Dan Titik Dua Dalam Kalimat 
Dengan Menggunakan Metode Latihan Siswa Kelas IV SDN Atananga. Fakultas Keguruan dan Ilmu Pendidikan Universitas Tadulako.

Astuti, S.D. dkk. (Tanpa Tahun) Peningkatan Kemampuan Menggunakan Tanda Baca Titik, Koma, Dan Titik Dua Dalam Kalimat Melalui Metode Diskusi Di Kelas IV SDN I Ogotua Kec. Dampal Utara. Fakultas Keguruan dan Ilmu Pendidikan Universitas Tadulako.

Nasution, H. (2013). Analisis Kesalahan Penggunaan Tanda Baca Karangan Argumentasi Siswa Kelas X Sma Negeri 4 Tanjungpinang.Tanjung Pinang: Universitas Maritim Raja Ali Haji.

Yera. (2014). Analisis Penggunaan Tanda Baca Dalam Karangan Narasi Siswa Kelas VII
Sekolah Menengah Pertama Negeri 3 Satu Atap Piabung Kabupaten Kepulauan Anambas Tahun Ajaran 2012/2013. Tanjun gpinang : Universitas Maritim Raja Ali Haji

Depdikbud. (2015). Pedoman Umum EBI.Jakarta

Tarigan, H.G. (2008). Menulis Sebagai Suatu Keterampilan Berbahasa. Bandung: Angkasa.

Suparno dan Yunus, M. (2003). Keterampilan DasarMenulis. Jakarta: Pusat.

Keraf, G. (2000). Argumentasi dan Narasi.Jakarta: Gramedia.

Munif, J. A. (2007). Mengenal JenisJenis Karangan. Satu Buku. 